\title{
Structural Synthesis of Parallel Manipulators Based on a Different Approach
}

\author{
Paralel Manipülatörlerin Farklı Bir Yaklașıma Dayalı \\ Yapisal Sentezi \\ Erkin Gezgin ${ }^{*}$ (10
}

1 İzmir Katip Çelebi Üniversitesi Mühendislik Fakültesi Mekatronik Mühendisliği Bölümü, İzmir, TÜRKIYE Sorumlu Yazar / Corresponding Author*: erkin.gezgin@ikc.edu.tr

Geliş Tarihi / Received: 15.09 .2018

DOI:10.21205/deufmd.2019216122

Kabul Tarihi / Accepted: 14.11.2018

Araștırma Makalesi/Research Article

Atıf sekli/How to cite: GEZGIN, E.. (2019). Structural Synthesis of Parallel Manipulators Based on a Different Approach. DEUFMD, 21(61), 225234.

\begin{abstract}
This work tries to address structural synthesis procedures of parallel manipulators in a different point of view. In generic methodology while structural synthesis starts from deciding the structure of the platforms and computing the structure of the legs in terms of specified constraints, proposed procedure follows an inverse analogy. After the determination of desired number of legs and subspace constraints of the whole manipulator, possible configurations of platform structures are extracted and checked for their constructability. Throughout the study proposed procedure was introduced in detail along with the constraint equations. Utilizing introduced procedure for given examples, structural groups of parallel manipulators were created with respect to the desired constraints and actuators were attached for mobility considerations. All of the results were tabulated throughout the study in order to form various kinds of parallel manipulators as parallel platform manipulators, serial platform manipulators, and serial-parallel platform manipulators.

Keywords: Structural synthesis, Parallel manipulators, Platform structures, Structural groups.
\end{abstract}

Öz

Bu çalışmada paralel manipülatörlerin yapısal sentez prosedürleri farklı bir bakış açısıyla ele alınmaya çalışılmıştır. Klasik yöntemlerde yapısal sentez ilk önce manipülatör platform yapılarının belirlenmesiyle başlamakta ve daha sonra belirtilen tasarım kısıtlamaları doğrultusunda bacak yapılarına geçilmektedir. Bu çalışmada önerilen yöntem ise klasik uygulamalara göre ters bir benzetimi takip etmektedir. Bu doğrultuda sunulan yöntem, tasarlanacak manipülatör için istenilen bacak sayıları ve çalışma uzayı kısıtları belirlendikten sonra, olası tüm platform yapılarının oluşturulabilmesini sağlamakta, kısıt denklemleri ile de oluşturulan yapıların geçerliliğini belirlemektedir. Çalışma içerisinde önerilen yöntem kullanılarak, verilen tasarım örnekleri doğrultusunda paralel manipülatörlerin yapısal grupları oluşturulmuş ve istenilen serbestlik derecesi kriterlerine göre gerekli eyleyiciler yerleştirilmiştir. Elde edilen sonuçlar, paralel platform, seri platform ve seri-paralel platform manipülatörlerinin oluşturulabilmeleri için tablolar içerisinde sunulmuştur.

Anahtar Kelimeler: Yapısal sentez, Paralel manipülatörler, Platform yapıları, Yapısal gruplar 


\section{Introduction}

Structural synthesis can be seen as one of the most important steps for the design of parallel robot manipulators. It is the first problem that should be covered by any designer as the coarse structure of the manipulator is revealed during this step with respect to the task requirements.

Throughout the literature many studies have been devoted to the structural synthesis problem of parallel manipulators. Some of these studies only tried to address mobility calculation problems due to their complexity for closed loop manipulators, while others introduced new design methodologies to construct various types of parallel manipulators. Studies on the kinematic structure of mechanisms were reviewed in detail by Mruthyunjaya [1]. In his review, author utilizes extensive literature to show advances, contributions and future directions of the field. Alizade et al. [2,3,4,5] proposed new design procedures for various parallel manipulator types ranging from parallel manipulators, serial platform manipulators, Euclidean platform manipulators and overconstraint parallel manipulators. In their studies, procedural approaches were introduced and proposed along with novel mobility equations. Utilizing introduced procedures, authors have designed various robot manipulators with different mobilities. Moreover, in their work that is related with serial platform manipulators [3], history of mobility formulations in the literature of mechanism and machine science were given in detail in a compact table as a short review. Gogu [6] presented a new structural synthesis approach for the design of fully-isotropic translational parallel manipulators. During the study, it is revealed that, all possible structural solutions of these manipulators could be obtained by utilizing proposed methodology. Li et al. [7] developed a new structural synthesis method for planar mechanisms. In their study, authors utilized Assur groups as elements of developed adjacency matrix to derive various types of planar mechanisms that include revolute and prismatic joints. Yan et al. [8] provided an extensive literature review on the number synthesis of kinematic chains with simple joints. Various methods on the subject were presented and discussed throughout the study. Variations of kinematic chain definition between different authors that have studies on the subject were also revealed and discussed. Corves [9] et al. presented a systematic structural design methodology for translational parallel manipulators with redundant actuations. During their study, based on the proposed methodology, two valid configurations of parallel manipulators were analysed. At the end of their study authors proved that, redundant actuation on parallel manipulators has positive effects on the positional accuracy due to the fact that the end effector force distributions are improved. Palpacelli et al. [10] utilized screw theory in the mobility analysis of reconfigurable parallel manipulators. Hao et al. [11] introduced a new structural design method for compliant parallel manipulators with actuation isolation. In their method authors proposed the addition of actuation legs to the manipulator with respect to its original degrees of freedom. Two case studies related with the proposed approach were introduced and one of them was studied by analytical modelling. Rico et al. [12, 13] utilized group theory and Lie Algebra for the mobility analysis of kinematic chains. During their work authors presented a short review on the analysis of degrees of freedom of linkages and they presented a new mobility criterion along with its algebraic formulation. Kong et al. [14] introduced a systematic type synthesis approach by utilizing virtual kinematic chains for the design of parallel manipulators. In their approach, considering the platform motion pattern, a serial virtual chain is selected and by following the presented procedures various parallel manipulators are able to be designed. Yang et al. $[15,16]$ presented another novel formulation for the calculation of degrees of freedom of mechanisms. In their studies, introduced single open chain composition principle was proved as an efficient approach for the topological analysis and the synthesis of parallel mechanisms. Authors have extended the application of the principle from planar mechanisms to spatial mechanisms at their latter study.

As it can easily be seen in this brief literature review, many researchers have tried to implement new methodologies into the structural synthesis problem of parallel robot manipulators by considering the advancements throughout the literature. In the light of these investigations, this paper tries to develop a new 
structural synthesis procedure for parallel manipulators from various subspaces by considering a different approach. Instead of starting with the decision of platform structure and configuring the legs of the manipulator afterwards, introduced structural synthesis procedure starts from specifying the desired number of legs of the manipulator and progresses into the selection of its platform configuration from possible options. In order to justify this method, any design case can be given where the actuators of the manipulator have to be located on the fixed ground to avoid usage of bulky links to carry the unwanted floating actuators. It is clear that this can only be fulfilled by utilizing the same number of legs with the mobility requirement of the task. Opposite of this scenario is also valid in which possible leg connections on the task workspace are limited and less than the desired mobility that results in the necessity to focus on the leg number as well as utilizing floating actuators. Thus proposed approach will be more efficient for a designer as the main concern of the design is to reach necessary mobility requirements by utilizing specific number of legs. Additional design scenarios can also be given such as the mechanism design case of a mobile manipulator for the rough terrain compensation where the actuators are the wheels and number of them strictly specifies the number of necessary legs on the system.

In pursuance of a creation of discussed design procedure, some assumptions were taken as below,

- All designed manipulators should have independent loops from a single subspace,

- All designed manipulators should have at least one non-actuator joint on each of their legs,

- Type of the designed manipulators should be restricted as parallel platform manipulators, serial platform manipulators and serial-parallel platform manipulators.

With respect to these assumptions preliminary equations were formed for the development of introduced structural synthesis procedure that will be discussed throughout the paper.

This study includes detailed presentation of the proposed methodology and its application through various design examples in a simple organization. Structural formula and preliminaries section discusses the formation of necessary constraint equations. In this section, basic information regarding with the usage of selected mobility equation and structural synthesis can be found. Following section includes the discussion about the proposed structural synthesis procedure where the main approach and its necessary steps are explained in detail. Throughout this section various examples are presented to clarify the proposed methodology. At the end of the study discussions are given in the conclusions section.

\section{Structural Formula and Preliminaries}

It is an easy task to design any kind of parallel robot manipulator with desired mobility configuration once its structural group is constructed. In simple terms structural groups can be described as primitive versions of their manipulator counterparts with zero degrees of freedom. They can be designed by the generated procedures with respect to the suitable mobility formulations dedicated to their specific manipulator types. Due to the fact that several mobility criterions exist in the literature, it is important to choose the most suitable one prior to the procedural approach as some of them are not valid for all manipulator types. Considering these facts and design assumptions of this study, modified version of Alizade's universal mobility formulation (Eqn.1) for the manipulators that contain independent loops from a single subspace will be used for the rest of the study as,

$$
M=\sum_{i=1}^{j} f_{i}-\lambda L, \quad L=N-C-B
$$

where $M$ is the mobility of the manipulator, $\mathrm{j}$ is the number of joints, $f_{i}$ is the degrees of freedom of the $i^{\text {th }}$ joint, $\lambda$ is the dimension of the motion space, $L$ is the number of independent loops, $N$ is the total number of joint connections on platforms, $C$ is the total number of connections between platforms, and $B$ is the total number of platforms.

As the study focuses on parallel platform manipulators, serial platform manipulators, and serial-parallel platform manipulators, connections between platforms are only possible via kinematic chains (branches for parallel platform manipulators), single revolute joints (hinges for serial platform manipulators) or both at the same time (serial-parallel 
platform manipulators). Thus total number of connections $(C)$ can be rewritten as,

$$
C=c_{b}+c_{h}
$$

where $c_{b}$ is the total number of branch connections and $\mathrm{ch}$ is the total number of hinge connections between platforms. Each connection, either branches or hinges, requires two joint connection allocations from moving platforms, and remaining joint connections on the platforms should be connected to the legs. Thus the number of the legs $\left(C_{l}\right)$ can be calculated as,

$$
C_{l}=N-2\left(c_{b}+c_{h}\right)
$$

Single platform structures that will be used throughout this study consist of triangular, rectangular, pentagonal and hexagonal platforms (Fig.1), so the smallest and the largest number of joint connections that any platform can hold will be considered as three and six respectively.

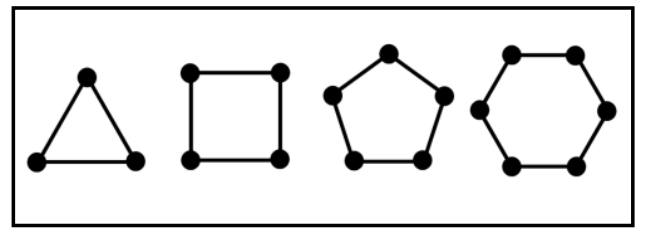

Figure 1. Platforms with $3,4,5$ and 6 elements

In the light of this, minimum and maximum total number of joint connections on the platforms of the manipulator will be,

$$
N_{\text {min }}=3 B, N_{\text {max }}=6 B
$$

Also by assuming all the platforms are either triangular or hexagonal, minimum and maximum achievable number of connections can be calculated by combining Eqn. 3 and Eqn. 4 as,

$$
\left|\frac{3 B-C_{l}}{2}\right| \leq c_{b}+c_{h} \leq\left|\frac{\left(6 B-C_{l}\right)}{2}\right|
$$

Note that, these connections (hinges and branches) should be formed between distinct platforms and if the branch or hinge connections on the platforms are to be creating loops, loops should be designed in a way that the total number of degrees of freedom of all joints within each loop $\left(\sum f_{L_{i}}\right)$ must be greater than the dimension of the motion space $(\lambda)$ of that loop. Otherwise the loop will behave as a rigid platform.

$\sum f_{L_{i}}>\lambda_{L_{i}}$

By the combination of this idea with the assumed constraint where all designed manipulators will have at least one nonactuator joint on each of their legs, additional design criteria formulation can be introduced for the structural groups as,

$\lambda L \geq N+\sum_{i=1}^{n}\left(\lambda_{L_{i}}-3\right)$

where $\mathrm{n}$ is the number of loops created by the branch or hinge connections. Due to the fact that this study deals with manipulators from uniform single subspace Eqn.6 and Eqn.7 can be modified as,

$\sum f_{L_{i}}>\lambda, \quad \lambda L \geq N+n(\lambda-3)$

Additionally, in order to avoid actuator misplacements that will create undesired motions, total degrees of freedom of all joints on any leg $\left(\sum f_{l_{i}}\right)$ should be less than the sum of number of actuators on that leg $\left(\mathrm{m}_{\mathrm{i}}\right)$ and the dimension of the motion space (Eqn. 9).

$\sum f_{l_{i}}<\lambda+m_{i}$

It is vital that all design criterion equations (Eqn.4 - Eqn.9) must be considered in order to design a valid parallel manipulator.

\section{Structural Synthesis}

Usual structural synthesis procedures involve the decision of the platform structures first. These platform structures include the types and the numbers of the platforms, their connections and the loops within them. Structure of the legs are computed and designed after the platform configurations are decided by using suitable mobility criterions. However if the legs of the manipulator are the main concern of the design, a new procedure can be introduced for the structural synthesis. The main concern of the proposed method lies in the selection of the number of legs and computing valid possible platform structures by means of desired design 
criterions. Considering given leg requirements, the designer can choose from variety of platform setups and create parallel manipulators with distinct mobilities.

In the light of this, where the main design constraint is the number of legs, the designer should easily follow the procedure introduced below to design the desired parallel manipulator for the given task.

- Decide the dimension of the motion space $(\lambda \rightarrow 1, \ldots, 6)$.

- Decide the desired amount of legs $\left(C_{l}\right)$ as the main design constraint.

- Decide the number of platforms $(B)$ that is required for the task.

- Using Eqn.5, calculate the range of possible number of connections $(C)$ between the platforms.

- Distribute the values of possible connections $(C)$ between the number of branches (cb) and the number of hinges $\left(c_{h}\right)$. Map all the possibilities.

- Using Eqn.3 calculate the total number of joint connections on platforms $(N)$ for the calculated connection range.

- Considering decided number of platforms $(B)$, possible platform types (Fig. 1), and calculated number of joint connections on platforms $(N)$, form the possible platform configurations.

- Using the connection criterion (connections should be formed between distinct platforms), and Eqn.8, eliminate non-valid platform configurations.

- Using Eqn.1 calculate the necessary number of single degree of freedom joints to form the structural groups from the valid configurations.

- Distribute joints to the legs and connections homogeneously by also considering Eqn.6.

- If applicable use the exchangeability of kinematic pairs to use higher degrees of freedom joints by combining single degree of freedom joints.
- Considering desired mobility for the task and Eqn 9, place actuators to the legs.

- With respect to the space or subspace constraints adjust the geometrical alignments of the joints.

In order to understand this procedure clearly let's follow the simple design examples given below.

Example 1: A planar $(\lambda=3)$ parallel manipulator with four legs $\left(C_{l}=4\right)$ and a single platform $(B=1)$ is decided to be designed. Find all of the possible configurations and construct three degrees of freedom $(M=3)$ planar parallel manipulator from valid configurations.

Solution 1: As the dimension of the motion space, number of legs and number of platforms of the parallel manipulator are already given as design constraints, design procedure should be followed by calculating the range of possible number of connections by utilizing Eqn. 5 as,

$$
\left|\frac{3-4}{2}\right| \leq c_{b}+c_{h} \leq\left|\frac{(6-4)}{2}\right|
$$$$
-0.5 \leq c_{b}+c_{h} \leq 1
$$

Although it is clear that a single platform manipulator cannot have any connections between platforms, the sole purpose of this example is to validate the given procedure. As seen in Eqn.9, connection possibilities were revealed as integers, $c_{b}+c_{h}=0$ or $c_{b}+c_{h}=1$. Using these two possibilities, table 1 was constructed below showing the possible distributions of these constraints into the coarse manipulator structures by utilizing the proposed procedure.

It is clearly seen that three possible manipulator configurations were revealed. On the other hand, second and third configurations violate the design constraint of "connections should be formed between distinct platforms", thus there remains only one valid manipulator configuration for the given example to take as a solution. 
DEU FMD 21(61) 225-234, 2019

Table 1. Possible Distributions of Given Constraints for Example 1

\begin{tabular}{|c|c|c|c|}
\hline \multirow{3}{*}{$\begin{array}{l}\text { Connection } \\
\text { Possibilities }\end{array}$} & \multicolumn{3}{|c|}{$-0.5 \leq c_{b}+c_{h} \leq 1$} \\
\hline & \multirow{2}{*}{$c_{b}+c_{h}=0$} & \multicolumn{2}{|c|}{$c_{b}+c_{h}=1$} \\
\hline & & $c_{b}=1, c_{h}=0$ & $c_{b}=0, c_{h}=1$ \\
\hline $\begin{array}{c}\text { \# of Joint } \\
\text { Connections } \\
\text { on Platforms }\end{array}$ & $N=C_{l}+2\left(c_{b}+c_{h}\right)=4$ & $N=C_{l}+2\left(c_{b}+c_{h}\right)=6$ & $N=C_{l}+2\left(c_{b}+c_{h}\right)=6$ \\
\hline $\begin{array}{c}\text { Coarse } \\
\text { Platform } \\
\text { Structures }\end{array}$ & & & \\
\hline Validity & $\sqrt{ }$ & $x$ & $\mathrm{x}$ \\
\hline
\end{tabular}

Using this configuration and following the remaining steps of the design procedure, necessary number of single degree of freedom joints were distributed to the legs homogeneously to form the structural group of the manipulator (Fig.2a). After this step actuators were placed to the legs with respect to the desired mobility constraint (Fig.2b).

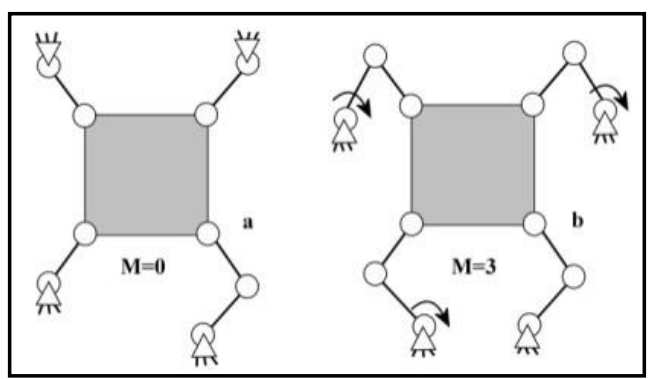

Figure 2. a) Structural Group of the Planar Platform Manipulator M=0 b) Planar Platform Manipulator with Three Actuators $\mathrm{M}=3$

Planar parallel manipulator shown in Fig.2 was represented by using revolute joints with parallel joint axes. These revolute joints can also be replaced by suitably oriented prismatic joints as long as there exist no more than two prismatic joints in any formed closed planar loop. It should be noted that different manipulator designs can be accomplished from the same structural group by changing the placements of the actuators as long as Eqn. 9 holds in order to avoid actuator misplacements that will create undesired motions.

As an example to undesired motion fact, let's again consider the structural group specifically shown in Fig. 2 to design a parallel manipulator with $\mathrm{M}=1$ for the ease of understanding. In order to design the specified manipulator by following the given design procedure, a single actuator should be placed to any of the legs. On the other hand, if the actuator is chosen to be placed to the leg that has already three revolute joints, the connected input will have no influence on the platform motion. Although the system will still have a single degree of freedom, revealed motions only occur at the links of the actuated leg due to a four bar like leg configuration in planar subspace. Unless it is a desired property, this kind of placements should be avoided by choosing another spot for an actuator.

In order to advance further to create different parallel manipulator types, let's apply the same 
procedure for multiple platform parallel manipulators.

Example 2: A planar $(\lambda=3)$ parallel manipulator with four legs $\left(C_{l}=4\right)$ and dual platforms $(B=2)$ is decided to be designed. Find all of the possible configurations and construct two degrees of freedom $(M=2)$ planar parallel manipulator from valid configurations.

Solution 2: As the dimension of the motion space, number of legs and number of platforms of the parallel manipulator are already given as design constraints, the same design procedure should also be followed for this example by calculating the range of possible number of connections by utilizing Eqn. 5 as,

$$
\begin{aligned}
& \left|\frac{6-4}{2}\right| \leq c_{b}+c_{h} \leq\left|\frac{(12-4)}{2}\right| \\
& 1 \leq c_{b}+c_{h} \leq 4
\end{aligned}
$$

As seen in Eqn.10, connection possibilities were revealed as integers, $c_{b}+c_{h}=1, c_{b}+c_{h}=2$, $c_{b}+c_{h}=3$ or $c_{b}+c_{h}=4$. In order to simplify the problem let's narrow down the case for the first two possibilities $\left(c_{b}+c_{h}=1, c_{b}+c_{h}=2\right)$. Using these two possibilities, table 2 was constructed below showing the possible distributions of these constraints into the coarse manipulator structures by utilizing the proposed procedure.

It is clearly seen that 18 possible parallel manipulator configurations were revealed that consist of parallel platform, serial platform, and serial-parallel platform types. On the other hand, only 6 of them are valid configurations for the given example as others violate the design constraint of either "connections should be formed between distinct platforms" or "loops should be designed in a way that the total number of degrees of freedom of all joints within each loop must be greater than the dimension of the motion space of that loop (Eqn.6)". Using valid configurations and following the remaining steps of the design procedure, necessary number of single degree of freedom joints were distributed to the legs homogeneously to form the structural groups of the manipulators. After this step actuators were placed to the legs with respect to the desired mobility constraint (Fig.3).

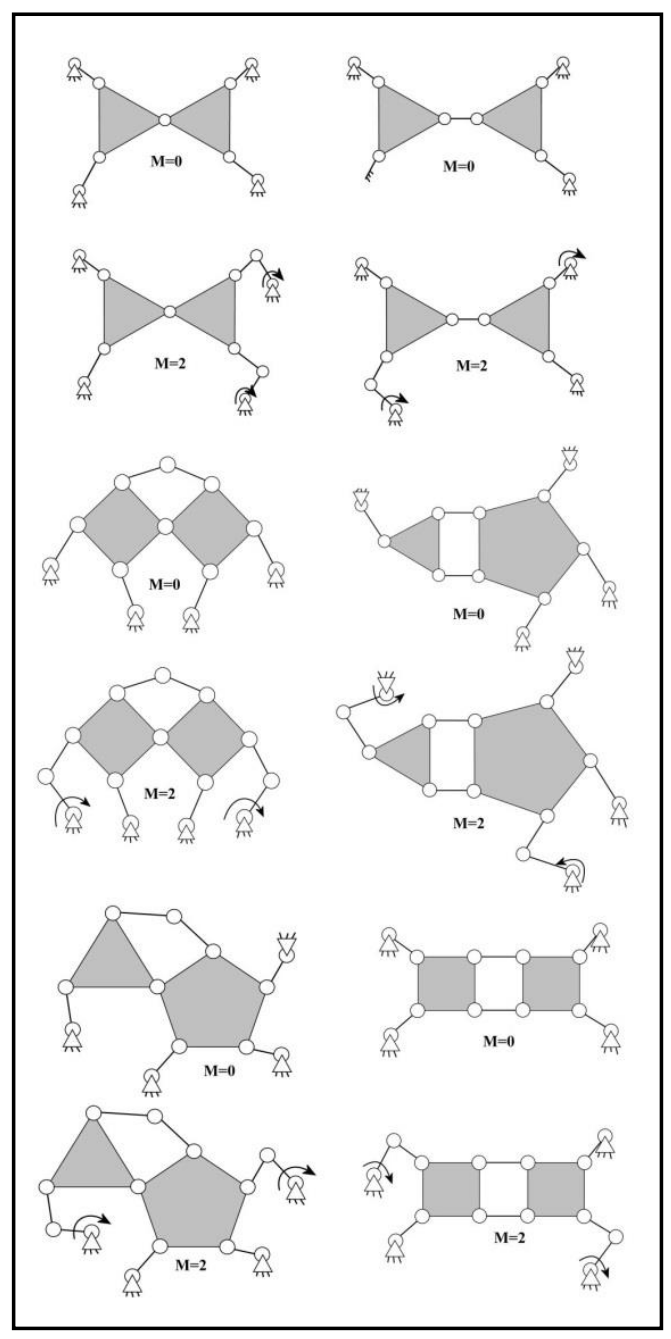

Figure 3. Valid Parallel Manipulators with $M=2$ for Example 2 and Their Structural Groups

Similar to the solution of example 1, all of the parallel manipulators were represented by using revolute joints and they can be replaced by suitably oriented prismatic joints as long as there exist no more than two prismatic joints in any formed closed planar loop. Remember that different manipulator designs can also be accomplished from the same structural groups by changing the placements of the actuators as long as Eqn. 9 holds. 
DEU FMD 21(61) 225-234, 2019

Table 2. Possible Distributions of Given Constraints for Example 2

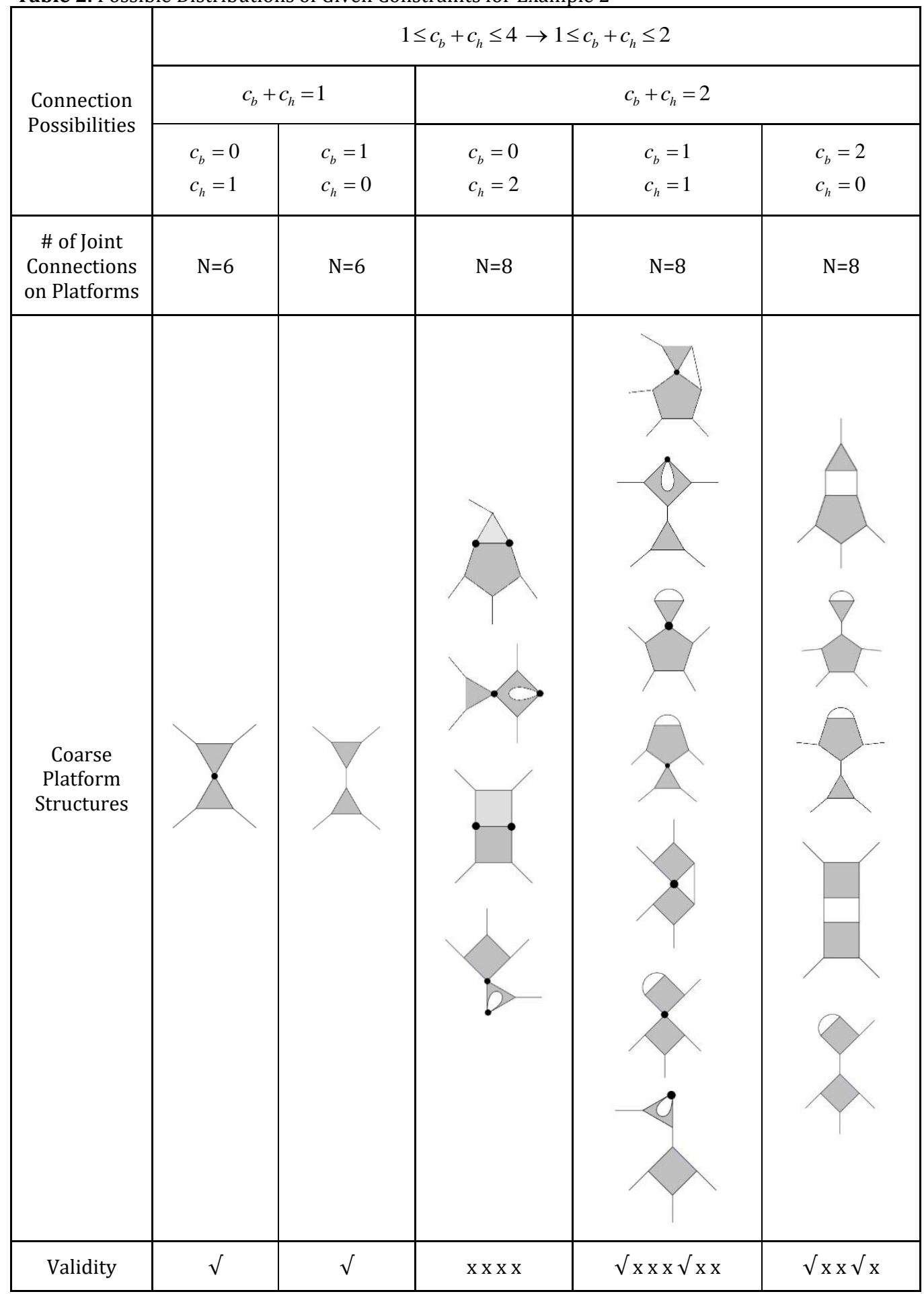


DEU FMD 21(61) 225-234, 2019

So far all of the examples were given from subspace three $(\lambda=3)$ where the resulting manipulator motion lies on a planar workspace. In order to represent the applicability of the procedure for other subspaces also, let's continue with a final example.

Example 3: A spatial $(\lambda=6)$ parallel manipulator with four legs $\left(C_{l}=4\right)$ and dual platforms $(B=2)$ is decided to be designed. Construct four degrees of freedom $(M=3)$ spatial parallel manipulator.

Solution 3: As all of the possible parallel manipulator configurations with valid results were already revealed for the manipulators with four legs in example 2, solution of this problem can be started by choosing any valid configuration from table 2 and calculating the necessary number of single degree of freedom joints by utilizing equation 1 . After applying exchangeability of the kinematic pairs and actuator placements design requirements of the example can be fulfilled. (Fig.4)

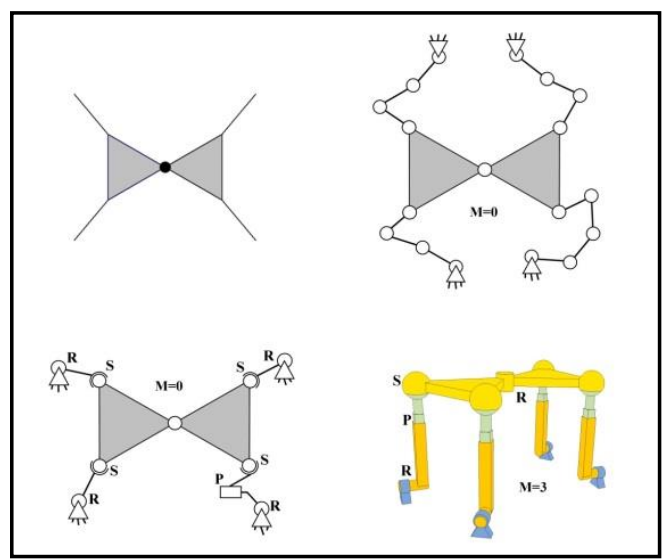

Figure 4. Procedural Approach for Example 3 (Selection of Manipulator Configuration, Placement of the Joints, Application of

Exchangeability of Kinematic Pairs and Final Parallel Manipulator after the Actuator Placements)

\section{Conclusions}

This study introduces a new procedure for the design of parallel platform manipulators where the main design consideration is the total number of legs that will be desired to be used for the given task. Once the leg number is decided, considering the introduced design criterions, any designer will be able to configure the platform structure of the parallel manipulator for the given task. Within the selection of valid configurations, different types of parallel manipulators can be constructed with respect to the task mobility requirements.

Throughout the study introduced design approach was clearly demonstrated step by step along with the related constraint equations and criterions. Various design examples were also given with their solutions. Considering given examples, 21 possible and 7 valid parallel manipulator configurations were demonstrated. Utilizing these valid configurations, 7 planar parallel manipulators and 1 spatial parallel manipulator were successfully constructed with desired mobility requirements.

It is shown that, presented procedure can successfully be applied for the design of different types of parallel manipulators from space and various subspaces. Future works of the study will include the platform configuration possibilities of the overconstrained parallel manipulators along with their geometrical constraints.

\section{References}

[1] Mruthyunjaya, T. S. "Kinematic structure of mechanisms revisited." Mechanism and machine theory 38, no. 4 (2003): 279-320.

[2] Alizade, Rasim, and Çağdaş Bayram. "Structural synthesis of parallel manipulators." Mechanism and machine theory 39, no. 8 (2004): 857-870.

[3] Alizade, Rasim, Cagdas Bayram, and Erkin Gezgin. "Structural synthesis of serial platform manipulators." Mechanism and Machine Theory 42, no. 5 (2007): 580-599.

[4] Alizade, Rasim, Ozgun Selvi, and Erkin Gezgin. "Structural design of parallel manipulators with general constraint one." Mechanism and Machine Theory 45, no. 1 (2010): 1-14.

[5] Alizade, Rasim, Fatih Cemal Can, and Erkin Gezgin. "Structural synthesis of Euclidean platform robot manipulators with variable general constraints." Mechanism and Machine Theory 43, no. 11 (2008): 1431-1449.

[6] Gogu, Grigore. "Structural synthesis of fullyisotropic translational parallel robots via theory of linear transformations." European Journal of Mechanics-A/Solids 23, no. 6 (2004): 1021-1039.

[7] Li, Shujun, Hongguang Wang, and Jian S. Dai. "AssurGroup inferred structural synthesis for planar mechanisms." Journal of Mechanisms and Robotics 7, no. 4 (2015): 041001.

[8] Yan, Hong-Sen, and Yu-Ting Chiu. "On the number synthesis of kinematic chains." Mechanism and Machine Theory 89 (2015): 128-144.

[9] Corves, Burkhard, Jan Brinker, Michael Lorenz, and Martin Wahle. "Design methodology for translational parallel manipulators exhibiting actuation redundancy." Proceedings of the Institution of Mechanical Engineers, Part C: Journal of Mechanical Engineering Science 230, no. 3 (2016): 425-436. 
DEU FMD 21(61) 225-234, 2019

[10] Palpacelli, Matteo, Luca Carbonari, Giacomo Palmieri, and Massimo Callegari. "Mobility analysis of non-overconstrained reconfigurable parallel manipulators with 3-CPU/3-CRU kinematics." In Advances in Reconfigurable Mechanisms and Robots II, pp. 189-200. Springer, Cham, 2016.

[11] Hao, G. and Kong, X. "A structure design method for compliant parallel manipulators with actuation isolation.", Mech. Sci., 7, 247-253, https://doi.org/10.5194/ms-7-247-2016, 2016.

[12] Rico, José María, and Bahram Ravani. "On mobillity analysis of linkages using group theory." In ASME 2002 International Design Engineering Technical Conferences and Computers and Information in Engineering Conference, pp. 429-446. American Society of Mechanical Engineers, 2002.

[13] Rico, José M., J. Gallardo, and B. Ravani. "Lie algebra and the mobility of kinematic chains." Journal of Robotic Systems 20, no. 8 (2003): 477-499.

[14] Kong, Xianwen, and Clément M. Gosselin. Type synthesis of parallel mechanisms. Vol. 33. Springer, 2007.

[15] Yang, Ting-Li, and Dun-Jin Sun. "A general formula of degree of freedom for parallel mechanisms." In ASME 2008 International Design Engineering Technical Conferences and Computers and Information in Engineering Conference, pp. 13791390. American Society of Mechanical Engineers, 2008.

[16] Yang, Ting-Li, Anxin Liu, Hui-Ping Shen, Lu-Bin Hang, and Qiaode Jeffrey Ge. "Composition Principle Based on Single-Open-Chain Unit for General Spatial Mechanisms and Its Application." Journal of Mechanisms and Robotics (2018). 